\title{
La casa propia y la casa del otro: Visiones de las casas por dentro en el cine
}

\author{
Carolina Sanabria
}

Artículo

Afiliación: Universidad de Costa Rica, San José, Costa Rica

\section{E-mail: csanabriacr@yahoo.com}

Recibido: 13 de noviembre del 2018

Aceptado: 12 de abril del 2019

*Este artículo es el resultado de un proyecto de investigación en el Instituto de Investigaciones en Arte (IIARTE) de la Universidad de Costa Rica

\section{Resumen}

El presente artículo explora las dimensiones del tópico artístico de las casas por dentro en filmes contemporáneos -partiendo del referente fundamental, Rear Window (1954) de Alfred Hitchcock-, a saber: Kika (1993) de Pedro Almodóvar, Animals ferits (2006) de Ventura Pons, El hombre de al lado (2009) de Mariano Cohn \& Gastón Duprat y Dans la maison (2012) de François Ozon. Estas visiones están dadas por los mismos protagonistas sobre la casa en dos variantes básicas: la casa propia y la casa del vecino. El estudio pretende una revisión interdisciplinaria y crítica de la arquitectura interior desde las dinámicas de la visión en una muestra de filmes contemporáneos a través de una focalización del acto visual de los personajes en torno a la casa. La aproximación a la casa se plantea en dos dimensiones básicas: como el territorio íntimo y el territorio ajeno que se mira -en un acto que necesariamente impone una distancia, una objetivación- porque suele mediar un deseo. Por tanto el trabajo articula y confronta conceptos operativos como intimidad, mironismo, falta y thalamós, entre otros, que interactúan entre sí. El resultado produce variaciones de percepción del entorno doméstico de los personajes en esta muestra representativa que parte de la casa como un lugar más allá del mero espacio físico.

Palabras clave: arquitectura doméstica ; casa; interior; intimidad; visión.

One's home and other's home:

Visions of houses from the inside in films

\section{Abstract:}

This article explores the dimensions of the artistic cliche of the inside of houses in contemporary film -as of the fundamental referent of Rear Window (1954) by Alfred Hitchcock- in: Kika (1993) by Pedro Almodóvar, Animals ferits (2006) by Venutra Pons, El hombre de al lado (2009) by Mariano Cohn \& Gastón Duprat and Dans la maison (2012) by François Ozon. The visions of the home offered by the protagonists themselves are based on two basic variants: one's own home and the homes of one's neighbors. This paper sets out to present an interdisciplinary and critic review of interior architecture as of the dynamics of vision in a sample of contemporary films, through focusing on the visual act of the characters surrounding the house. The approach to the house is suggested in two basic dimensions: as intimate territory and as alien territory that is looked at -in an act that necessarily imposes a distance, an objectivation- because it usually mediates a desire. Thus, this paper articulates and confronts interacting operative concepts such as intimacy, voyeurism, error and thalamós, among others. The result produces variations of the perception of the domestic surroundings of the characters in this representative sample which begins from the house as a place beyond a mere physical space.

Keywords: domestic architecture; home; indoor; privacy; vision. 
esde los antiguos griegos, la dimensión doble del sujeto -pública y hogareña, de la polis y el domus- estaba perfectamente identificada. No obstante, en la historia, la atención a los ámbitos domésticos ha quedado opacada frente a la fascinación por lo grandioso y superior, por la epopeya y las grandes gestas, por el macrocosmos que conllevó, de acuerdo con Javier Echeverría, a una minusvaloración de lo íntimo, es decir, a lo que acontecía en el microcosmos (1999, pp. 27-28). No en vano la épica resultó un género que fue desarrollado desde la Grecia clásica y se continuó en la Edad Media, como lo corrobora la abundancia de cantares de gesta. De este modo, durante siglos no se dispuso de su correspondiente o contrapartida hasta el surgimiento, bastante más posterior, en el siglo XVIII, del melodrama, que remite fundamentalmente al interior no solo de los personajes sino también de sus viviendas. De ahí se sigue que la casa no funciona como una instancia indiferente y ajena a eventos históricos, sino que en ella se produce lo que se gesta afuera, como había planteado Guy Métraux: "Houses have content -they are not neutral instances of historical situations but active environments responsive to taste, desire, necessity and ambition" (1999, p. 396).

\section{Interior e intimidad}

En efecto, el lugar por excelencia de la intimidad -una invención surgida en el siglo XVIII- es la casa. La casa lleva implícita una relación entre lo interior y lo exterior que va más allá de los muros que se levantan. El concepto del interior doméstico, la densidad de la decoración, el tamaño y función de las habitaciones, los muebles contenidos ha variado a lo largo de la historia. Sin embargo, como dice el arquitecto canadiense Witold Rybczynksi, "el interior doméstico ha mostrado siempre una sensación de intimidad y de hogar" (2012, p. 221). Si el interior pertenece a la esfera privada, íntima, el exterior, en cambio, es por definición público. Esa relación que separa lo de fuera y lo de dentro es constitutiva de la naturaleza humana y está presente en distintas manifestaciones del arte: pintura, cine, literatura. "Tradicionalmente la historia de la vida privada se limita a la de la familia" (Nora citada en Ariès \& Duby, 2001, p. 159), y el lugar de esta es la casa, el lugar de intimidad.

En prácticas culturales que trabajan con la ficcionalización de esos espacios reservados como la literatura, la primera referencia la ofrece uno de los primeros textos de la épica grecolatina, La Odisea, que se enmarca tras el término de la guerra de Troya. El poema griego ha suscitado innumerables estudios desde muchos enfoques, pero en general no se le suele considerar desde la óptica tratada por el mencionado filósofo Echeverría, como la narración de una guerra doméstica que, según sus términos, se libra estancia por estancia (1999, p. 27): los pretendientes, aprovechando la ausencia de Odiseo, y disputándose el desposorio de Penélope, habían logrado adueñarse de la cocina, el patio y el salón.

El binomio de arquitectura y naturaleza aparece con frecuencia en la tendencia a identificar el interior con la subjetividad personal, en donde la experiencia de vida está en el cuerpo, por lo que el interior es cobijo y seguridad, mientras que el exterior es lo que está fuera del sujeto, lo desconocido y lo inseguro, como apunta Navarro de Zuvillaga: "Normalmente, el interior se representa con una habitación y el exterior con un paisaje (urbano o natural) y la relación entre ambos se manifiesta mediante la ventana y también con la puerta o el arco" (2000, p. 94). Mientras que las ventanas establecen con el exterior una comunicación visual, las puertas invitan a la acción (Navarro de Zuvillaga, 2000). En todo caso, ambos, ventana y puerta son umbrales que permiten el flujo de la visión.

La dualidad interior-exterior contiene una confrontación que Villatoro Lamolla, el ex Director del Centro de Cultura Contemporánea de Barcelona (CCCB) en el catálogo de la exposición $1000 \mathrm{~m}^{2}$ de deseo. Arquitectura y sexualidad plantea en esos dos términos que titulan la exhibición: "Una y otra son cultura, en el sentido clásico, en contraposición a la naturaleza. Una y otra son también política, en la construcción y la disputa, sobre lo que es compartido. Aparentemente, el deseo está en el núcleo más protegido de la intimidad, y los espacios del deseo han sido sobre todo muros para protegerlo" (2016, p. 21). Lo que está a la base de esta contraposición es el deseo, que se mezcla con la disposición urbana y la arquitectura. 
Las representaciones en el cine, lo mismo que en la pintura, suelen recurrir a estas aberturas materiales en tanto funcionan como una eficaz medicación entre el interior y el exterior. En el crecimiento de la filmografía llegan a dar pie a narrativas realistas, pero también postclásicas o manieristas como define el teórico David Bordwell. Este movimiento, extraído de la pintura del Renacimiento, toma cierta distancia de la estructura clásica y surge a partir de los años 50 en el cine estadounidense con la introducción de un grado de desconfianza o evidencia de la incerteza ante lo representado. Se pone en cuestión la transparencia de la cámara. En otras palabras, con el manierismo se desarrolla la conciencia del filme como representación, pero sin llegar a proponer una ruptura sino una distancia tan sutil que se percibe como una continuidad. Se logra a través de ligeras desviaciones y transgresiones con base en una reflexividad sostenida a grandes rasgos en artilugios como espejos, reflejos que profundizan en torno a las variaciones y posibilidades del acto mismo de mirar. Son films donde se mira a los personajes mirar. Es el caso de Alfred Hitchcock, cuyas narraciones se limitan al punto de vista de un personaje, por lo que subraya "por medio de la extraordinaria insistencia (...) en la subjetividad óptica" (Bordwell, Staiger \& Thompson, 1997, p. 88). A partir entonces de supresiones que producen suspenso en la narración y la adhesión a la perspectiva de un personaje, el director inglés desarrolla sus historias con protagonistas que miran hacia todas partes y siempre alinean al espectador con su visión en un fenómeno cinematográfico que estructura tanto las formas de ver como el placer de la mirada (Mulvey, 1988, p. 3). Sobre este ejercicio de reflexividad funciona el manierismo en el film: "Al mostrar a la vez al personaje que mira y al objeto mirado, no sólo inscribe en el universo narrativo el acto de mirar, sino que además lo narrativiza" (González Requena, 1989, documento mimeografiado).

Desde luego, esta forma de representación de la intimidad no basta para la creación del clima en las narrativas, y ha de combinarse con otros mecanismos y códigos, como la utilización del espacio en donde se desenvuelven los conflictos. ${ }^{1}$ Del otro lado, del contracampo donde el acto de visualidad encuentra sus fundamentos en una pulsión -en este caso escópica-, se sostiene la mirada intrusa en estos rincones privados, a pesar de que se trate de una obra de ficción, pero ya se sabe que la convención se funda en la suspensión momentánea de la credibilidad en el espectador. Esta dinámica funciona entonces bajo una articulación de la escena íntima y de quien mira -a quien en otro lugar se trabajó desde la figura del voyeur (Sanabria, 2011), indisoluble a su vez de la escena íntima diferenciada-.

Propiamente en el interior, las representaciones fílmicas pueden desplegar sus posibilidades de representación con mayor holgura. En estos espacios de intimidad, el panorama fílmico y televisivo había gestado su convención, consolidada en las series cómicas de los años 50 y 60 , a través de las situaciones desarrolladas en platós que simulaban entornos interiores cerrados de domicilios, ubicados en una disposición para un espectador privilegiado, semejante al precinema. Es decir, la intimidad de un hogar es habitualmente el estudio de las sitcoms televisivas, desde un emplazamiento frontal y fijo de la cámara ante una sala con comedor que hace un tanto rígido el formato. En el cine, por sus posibilidades, es más dinámico y se desarrolla la inclusión de gran variedad de espacios de los hogares como salas, cocinas, habitaciones.

\section{La casa del otro}

1 Tradicionalmente ha sido el ámbito hogareño. Javier Echeverría distingue, a ese respecto, entre casa y vivienda. Mientras que para él la última alberga a moradores, la casa, en cambio, no contiene necesariamente personas: puede haber animales, riquezas, muebles, recuerdos o incluso recintos sagrados y misteriosos donde moran los muertos o los espíritus (1999, p. 25).
El interiorismo de la vivienda está relacionado con la intimidad, que ha sido tema especialmente de la literatura romántica surgida entre los siglos XVIII e inicios del XIX como forma de expresión de las individualidades y se ha consolidado posteriormente en la ideología burguesa de la modernidad. Por eso, el precedente del personaje que explora en las intimidades ajenas proviene de un tipo que emerge más atrás, alrededor del siglo XVII en los cuadros de costumbres que caricaturizan los vicios privados. En efecto, una serie de cantos, refranes y expresiones de la cultura popular, se llegaron a formalizar en la novela satírica El diablo cojuelo (1641) de Luis Vélez de Guevara. Su autor utiliza una figura mágica que no se representaba como maligna, sino como un ser mágico travieso o curioso en una serie de andanzas acompañado por el atribulado don Cleofás y que tenía la propiedad de sobrevolar por encima de los tejados de la ciudad de Madrid y levantarlos para husmear las intimidades ajenas. 
El cine participa de esa vocación interiorista de la literatura y, dado que se trata de una práctica justamente visual, su puesta en imagen en ocasiones llega a suponer una problematización que adquiere especial fuerza reflexiva. Entonces se genera un procedimiento consistente en una mise-en-abyme, cuyo modelo prototípico elabora Alfred Hitchcock en Rear Window ${ }^{1}$ con base en el cuento "It Had to Be Murder" (1942) de Cornell Woolrich desde un argumento que a su vez evoca la trama de otro relato, "Through a Window" (1848), del británico H. G. Welles. En todos estos textos literarios y también el fílmico se parte de un protagonista inactivo que, para evitar el aburrimiento, pasa todo el tiempo mirando a otros personajes que desconocen ser observados, los vecinos de los edificios de enfrente. Es una situación que reproduce la dinámica visual prevista por Jeremy Bentham, el filósofo que diseñó la estructura mental del panóptico, en donde el protagonista asume el lugar de la ley porque la instancia policial resulta tan ineficiente que se niega a darle crédito. El protagonista integra en su visión espectáculo y vigilancia y se dedica día y noche a darle seguimiento a su pantalla tridimensional que termina revelándose peligrosa y casi costándole la vida.

El inicio empieza exactamente recordando al espectador que se encuentra posicionado ante una situación de ficción, con el movimiento de las cortinas que se abren para que acceda a la ventana que hará las veces de pantalla (Figura 1). La visión que obtiene Jeff es en cierto modo análoga a la de Ramón (Àlex Casanovas), el protagonista de Kika (1993) de Pedro Almodóvar, en virtud de que el estilo de la construcción de inmuebles resulta muy similar: grandes, altos e impersonales bloques de pisos -que dan la impresión de enjaular a sus habitantes-, a pesar de que correspondan a países de dos continentes distintos: un suburbio neoyorkino y una gran ciudad en Madrid (Figura 2). A diferencia en ambos casos de la novela de Vélez de Guevara, la visión no emana desde arriba, como en cenital (salvo el momento inicial en que, desde la perspectiva aérea de unos pícaros sujetos en helicóptero, la cámara se acerca para mirar a unas jóvenes tomando sol en los tejados). Rear Window procede de otra forma menos excéntrica y más propicia a la identificación del espectador, semejante a la del protagonista de Kika (1993): como una toma (casi siempre subjetiva) a nivel, posicionándose como un personaje (Jeff) que mira desde la ventana en una distancia que impide visualizar detalles pero que se solventa con equipo adecuado como prismáticos y lentes de acercamiento.

Figura 1. La vista de Jeff

Fuente: Hitchcook, A. (Director). (1954). La ventana indiscreta,

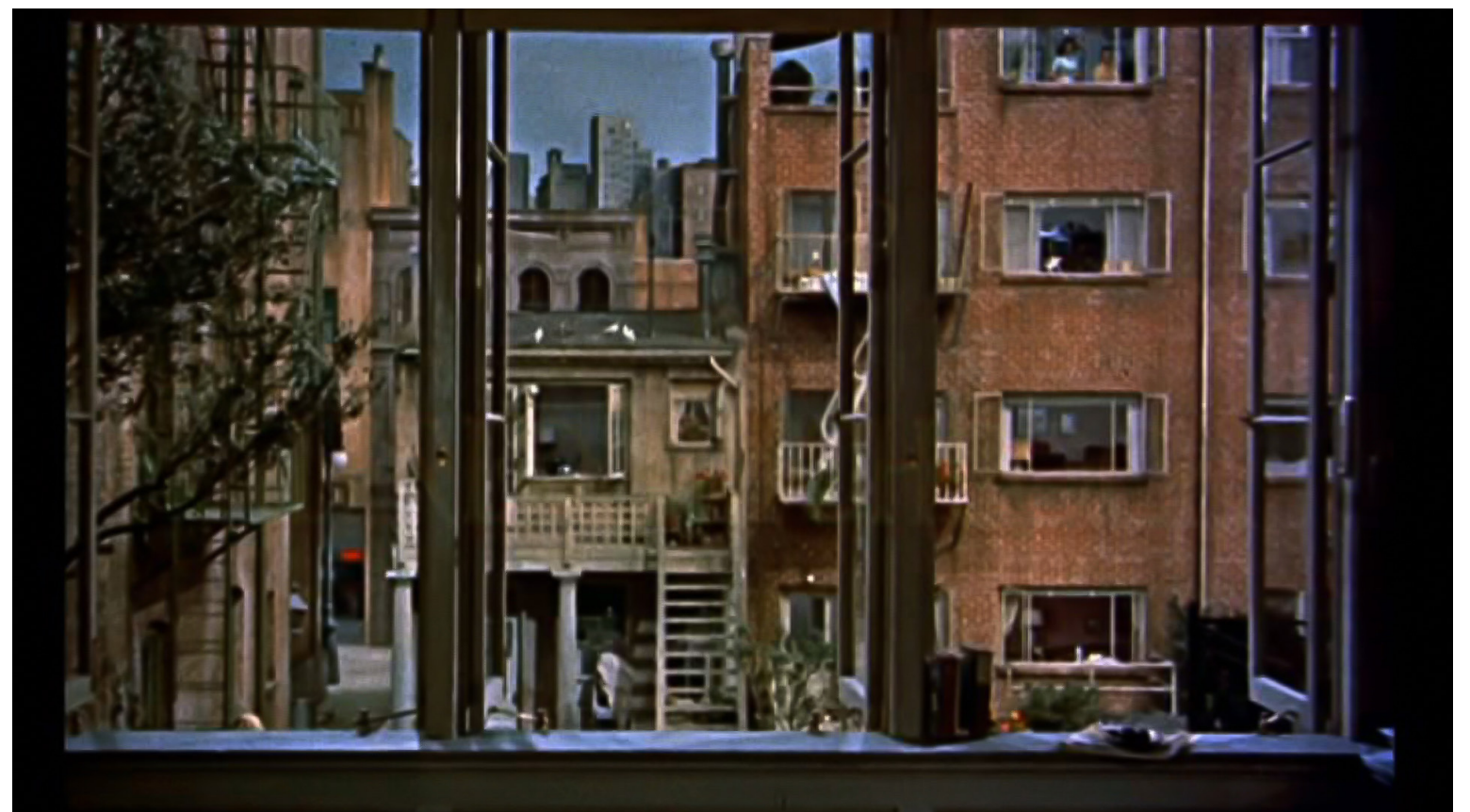

Evidentemente la intimidad supone una conjunción de factores, la de una estructura cuya visualización se ve favorecida por una pulsión visual connatural a la especie animal. A eso habría que sumarle que el vecino se visualiza normalmente en confrontación, como el otro, como el antagónico, el enemigo, que amenaza la privacidad. La mirada sobre la intimidad ajena es un fenómeno aún más extendido, al menos en narraciones fílmicas y también literarias, sobre la base de que en el polo de recepción existe una necesidad irracional que no se basta con la insuficiencia de la cotidianidad propia y requiere de historias, como diría Javier Marías al respecto de la literatura, pero también oportuno para la cinematográfica: "Suele hablarse (...) de la parvedad de nuestras existencias reales, de la insuficiencia de limitarse a una sola vida y de cómo la literatura 
Figura 2. La vista de Ramón. Fuente: Almodòvar, A. (Director). (1993). Kika nos permite asomarnos a otras o incluso vivirlas vicariamente, 0 atisbar las nuestras posibles que descartamos o que quedaron fuera de nuestro alcance o no nos atrevimos a emprender" (2008, p. 36).

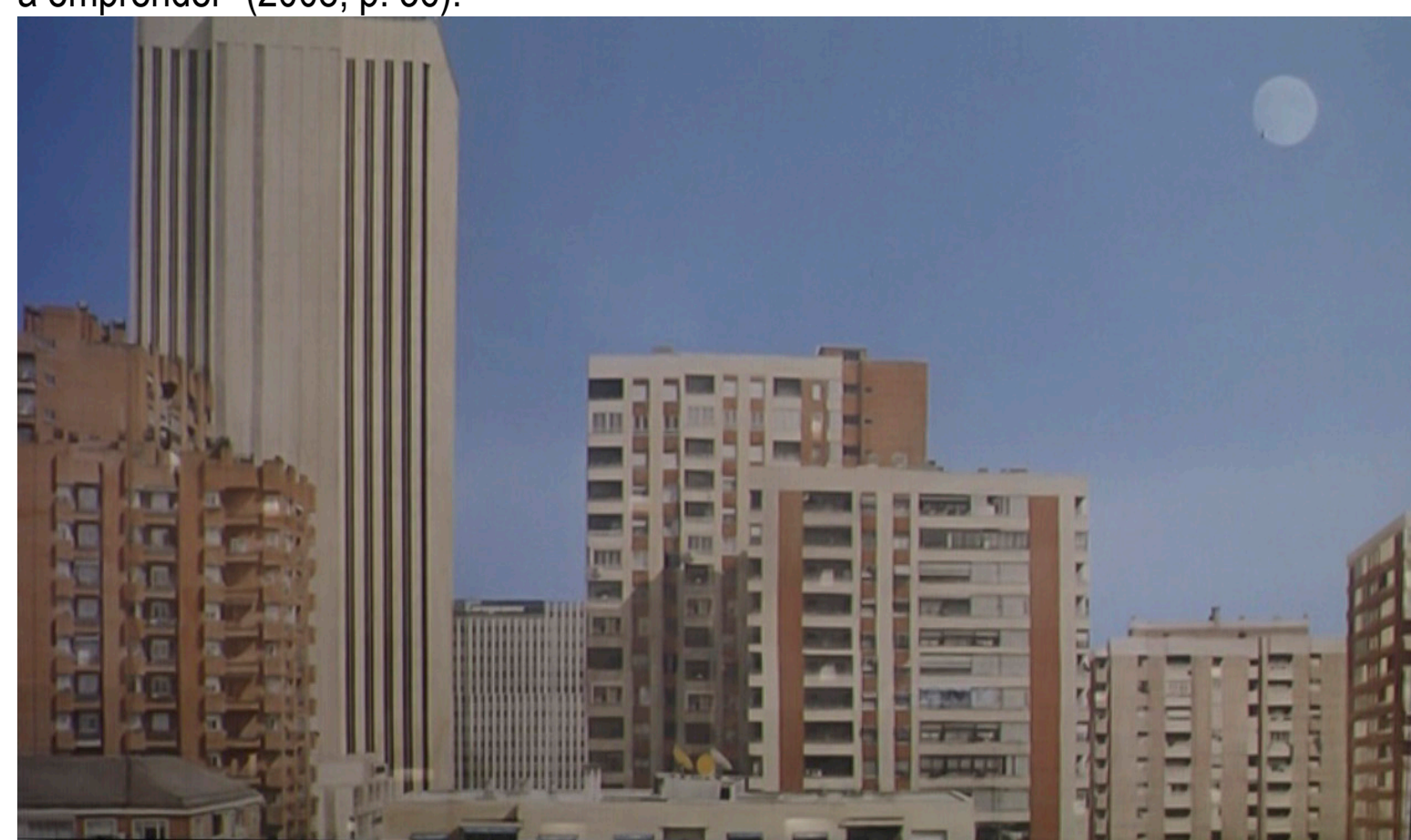

La película argentina El hombre de al lado (2009) de Mariano Cohn y Gastón Duprat articula su drama en torno a un conflicto por una ventana. El filme lo plantea desde el inicio, con el bicromatismo en las paredes: blanca de un lado (del buen vecino) -como el resto de la casa, la Curutchet, la única diseñada por Le Corbusier en América- y oscura del otro (del vecino problemático), lo cual ayuda a radicalizar la distancia entre ambas partes, racializando y criminalizando las diferencias sociales (Mouguillansky 2014, p. 156). Una vez que transcurren los créditos y se desliza la split screen, el emplazamiento de cámara queda ubicado en la casa de Leonardo, lo que invita al espectador a compartir la perspectiva -sustentada en argumentos lógicos, racionales, legales- de su problema. Al otro, al vecino, no lo asisten ni la razón ni la legalidad pero sí la empatía que se vuelve más paulatina conforme sucede la película a pesar de no se mantenga nunca su perspectiva.

En una primera conversación, el diseñador Leonardo (Rafael Spregelburd) le había pedido a su tosco vecino Víctor (Daniel Aráoz) que cerrara el boquete de la medianera a fin de evitar el mutuo contacto visual sobre la intimidad ajena de su espacio. Sin embargo, este enfáticamente se niega, argumentando que no piensa mirar al interior porque, según sus palabras, no es un psicópata ni se escandalizará si llega a ver "una bombacha colgada". A la mañana siguiente, en una conversación con su esposa Ana (Eugenia Alonso) cuando esta lo incita a averiguar en qué consisten los ruidos de su vecino, Leonardo responde: "No, ni en pedo... Yo no me voy a meter en la vida de otro tipo...." Irónicamente, tras el corte, la escena siguiente muestra al protagonista en el exterior palpando y con el oído a la pared, una forma de espiar distinta a la visual que había sido problematizada por Javier Marías en Todas las almas, donde el personaje reconocía que esta actitud de merodeo se amplía a lo auditivo, para lo cual el escritor madrileño había recurrido al anglicismo "eavesdropping" (1996). ${ }^{2}$ Por eso, como si no fuera suficiente -en realidad nunca lo es-, más adelante, una noche, Leonardo le dice a su esposa: "iEstá el vecino con alguien, vamos a espiarlo!" y se asoman a la ventana para fisgonear, ante lo cual ambos comentan divertidamente y ríen como adolescentes. El mironismo, que apriorísticamente tendería a identificarse más con el hombre vulgar de toscas maneras -como lo sugiere Ana- es practicado por el mundano Leonardo, de modo que conforma una pulsión que va más allá de condiciones sociales y que es más propia de la biología humana, del fenómeno conocido como cripsis, cuya razón de ser reside en funciones de autoconservación: su efecto, sintomáticamente llamado persiana, les permite a algunos organismos adoptar una forma o estructura análoga al entorno y permanecer en total inmovilidad a fin de evitar ser vistos mientras ven -lo que se traduce en situaciones de comer sin ser comidos-. Una de esas situaciones humanas se representa en la mirada sobre la intimidad ajena, como se metaforiza en la observación de la casa del otro, por lo general el vecino. 
En el fondo, hay un móvil pulsional en estos merodeadores de viviendas, que normalmente, como el paradigmático Jeff (James Stewart), realizan su inspección desde afuera bien pertrechado de equipo técnico que, al funcionar como extensiones del cuerpo, permite el acceso visual. Domina un deseo de franquear ese espacio intermedio para acceder al interior de las intimidades ajenas. En su caso, el límite llega a ser exacerbado cuando, una vez más, el vecino -esta vez sí atemorizante- Thorwald (Raymond Burr) prorrumpe intempestivamente en su casa tras haber enunciado la pregunta clave: "What do you want from me?".

Esta pregunta -motivo de sesudas discusiones de especialistas del filme- tiene su fundamento en la relación obsesiva del protagonista en quien se identifica el espectador con la imagen. En un ensayo de hace varios años, W. J. T. Mitchell, había afirmado que "[t]hey present, not just a surface, but just a face that faces the beholder" (1996, p. 72) -en donde se constata la importancia del sujeto que ejerce la acción-. Tras ello, el teórico hacía consciente su preferencia por postular la pregunta de lo que hacen las imágenes a lo que quieren, en un claro desplazamiento del incontestable poder hacia el deseo. "The painting's desire (...) is to change places with the beholder, to transfix or paralyze the beholder, turning him into an image for the gaze of the picture in what might be called 'the Medusa effect'" (1996, p. 76). Jeff es víctima de ese efecto Medusa -que también puede ser Narciso- en el que la imagen prácticamente adquiere independencia, lo que explica que la ventana específicamente de Thorwald sea tan subyugante. La razón no parece ser otra sino que este realiza el deseo inconfesable de Jeff -que resulta tan ignominioso por violento, el asesinato de su pareja Lisa (Grace Kelly)-. Por eso, como dice Mitchell, "[t]he power they want is manifested as lack, not as possession" (1996, p. 76).

La pregunta de Thorwald evidencia, pues, la articulación entre el sentido visual y el cognitivo del universo hitchcockiano y también es una de las formas en que se enuncia la pregunta por el deseo, como sostiene Pacteau: "Unavoidably, any relation to the other will be inhabited by the question of his or her desire: 'What do you want from me?' or 'How can I be your desire?"” (1994, p. 188). Esa irrupción violenta del vecino como el fondo de su pregunta hace que su interpelado se vea incapaz de responder. El hecho de esconderse detrás de la cámara y cubrirse los ojos implica una resistencia a ser visto: él es quien mira, se resiste a ser mirado. Tras el enfrentamiento físico, en el borde de la ventana, ambos se precipitan pero el protagonista queda colgando de la ventana de su mismo piso, que es como decir que cuelga del vacío del deseo. Como voyeur, Jeff ya se ha encontrado en el cuadro, fascinado por su propia presencia (Božovič en Žižek, 1994, p. 129). Esa atracción obsesiva que genera la ventana de Thorwald está en esa mancha que lo interpela por la razón de que lo contiene.

La ilusión de penetrar en la casa ajena parte siempre de un deseo, evidentemente escópico, que solapa complejidades inescrutables. Algo de eso se deja entrever en Dans la maison (2012) del director francés François Ozon, que constituye un claro y productivo homenaje a Hitchcock como lo recalca la escena del cierre (Figura 3). Una tarea del profesor de literatura Germain (Fabrice Luchini) es el desencadenante para que Claude García (Emmanuel Umhauer), el estudiante de la última fila -como es el título de la pieza dramática de Juan Mayorga que Ozon adapta-, sobresalga del resto. ${ }^{3}$ Su trabajo de redacción despunta de la mediocridad del salón y él, Germain, ve en el chico no solo el alumno ideal sino tal vez el hijo que no tuvo, el escritor que prometía ser y fracasó. El escrito consiste en una tarea sobre el fin de semana donde Claude, en vez de narrar sobre su propia vida, lo hace sobre su compañero de clase Rapha Artole (Bastien Ughetto) y sus padres. En toda la película se pone en escena a un jovencísimo protagonista que moviliza la trama desde la articulación de la mirada con el deseo: Claude asume el relevo de Jeff y resuelve sus limitaciones físicas no solo porque no está incapacitado para la movilización sino porque monta una ingeniosa argucia que le permite entrar directamente en la casa que lo obsesiona, donde puede penetrar en ella y deslizarse casi a su antojo por los pasillos, habitaciones y rincones. Si Jeff ingresaba a las intimidades ajenas a través de la ventana -y como si fuera poco, trasera ("rear")-, Claude lo hace por el otro de los umbrales de acceso -el principal, la puerta-, con su entera corporalidad y no de manera parcial (desde la visión). En su caso, la observación intimista de la realidad se combina en un escrito donde se fusionan el deseo, la imaginación y la carencia que, junto con un buen estilo narrativo, son propios 
Figura 3. Cartel de Dans la Maison. Fuente: François Ozoni (Director). (2012) En la casa. de todo buen escritor. Pero no solo eso: Claude termina describiendo la intimidad ajena entremezclada con la fantasía propia del autor que se repetirán al amparo de la guía literaria y el entusiasmo y que culminan siempre con un efectivo "(continuará)", ante lo cual el destinatario inmediato, Germain, como voyeur que también es, lo anima a continuar a pesar de que exceda los límites de la ética (y de la legalidad).

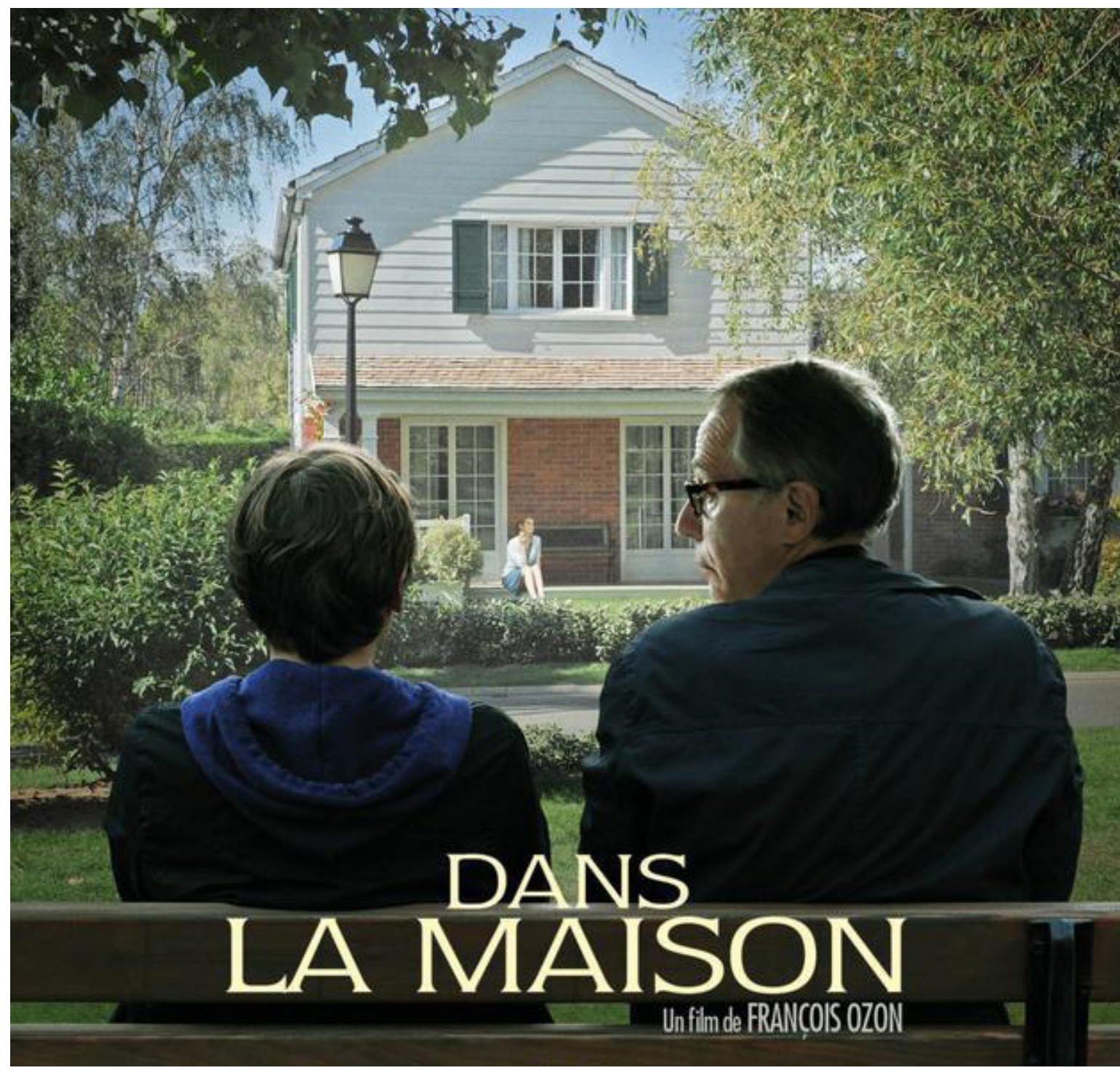

La amistad con Rapha le permite a Claude acceder a la casa e intimidad de una familia de clase media, según les llama sardónicamente en más de una ocasión. En efecto, con la escritura de cada informe o capítulo, el chico deja constancia asimismo de una posición distanciada e indirectamente superior, como caracteriza a cualquiera que mira. Pero en su caso, también resulta un sujeto patológico a pesar de su corta edad. Su estrategia es distinta y en cierto modo superior a la de Jeff porque lo observado está en función de la escritura que le permite un distanciamiento adicional y privilegiado -lo que produce una auténtica mediación: la palabra escrita-. Este procedimiento le evita integrarse del todo en la escena, mantener el poder de manipular los hilos de un universo real (por eso su narración no versa sobre seres de ficción imaginarios, como le había propuesto Germain en el momento del proceso) y sentirse, por consiguiente, observado -aun cuando fuera por él mismo-. Desde su ínfima menudencia (social, física), Claude no puede, se resiste a no desempeñarse como sujeto de la mirada y control de los acontecimientos y bajo ningún concepto objeto de la escena mirada, que para él es innegociable y para Germain el umbral de la caída.

La acción y la esencia del filme transcurren dentro de la casa de los Artole, donde el joven parece más cómodo que en la suya propia, quedándose hasta tarde o hasta pasar la noche con ellos, pero su propia rutina no se muestra sino cerca del desenlace del filme. Es entonces cuando el espectador vislumbra a comprender la razón por la que aparentemente frecuenta a los Artole: su vida es solitaria, con ausencia de la madre y a cargo de su padre físicamente incapacitado, en una silla de ruedas, con el que no se ve que se comunique. De la vivienda de su compañero, es en particular la madre Esther (Emmanuelle Seigner), un ama de casa interesada por la decoración de interiores lo que más atrae a Claude. Una explicación simple justificaría esta atracción por el complejo edípico y su falta: la ausencia de una familia nuclear como la de los Artole y el deseo de ocupar el lugar de Rapha, dado el eventual abandono de que podría haber hecho su madre. Sin embargo, tal argumentación es problemática en virtud de su capacidad de ingenio y retórica al servicio de la manipulación que favorece 
la ambigüedad. Así lo corrobora su vis a vis parcialmente elidido con Jane (Kristin Scott Thomas), a raíz de lo cual esta decide abandonar a Germain. Con la intrusión del joven esta vez en la vivienda del profesor se extrapola la pregunta de si ese dans la maison no estaría al final de cuentas referido a la casa de Germain en vez de la de los Artole y que todo lo ocurrido no fuera una maquiavélica estrategia para acceder a su interior.

Es claro, por lo demás, que la relación de Claude con Esther es imposible, y el desenlace con esta de nuevo preñada y los preparativos de la partida de la familia a China como deus ex machina exigen la desaparición de la familia y el desmantelamiento de la casa, que quedará puesta a la venta. No es la única casa que se cierra, porque algo parecido le sucede al final a Germain, pero a la inversa, cuando en la última escena Claude le dice a quien lo ha perdido todo que siempre estará a su lado. En el caso de los Artole, hay un desalojo de la casa; en el de Germain, una expulsión de la suya: el panorama resultante es una casa vacía y un hombre sin casa -no en vano viste como un indigente pese a estar en un sanatorio que se encuentra en la banca de un parque y cuyo contraplano final es ese conjunto de pisos habitados, insinuante del horizonte del filme de Hitchcock. ${ }^{4}$

\section{La casa propia}

Tal y como se representa en las narrativas fílmicas, la visión sobre la intimidad suele ejercerse habitualmente sobre la ajena. El caso de observación de la propia es distinto, como si no hubiera misterio, interés, atracción o morbo en la contemplación de los bienes propios. La excepción ocurre -eso sí- en condiciones de ausencia del dueño o del morador. Si llega a existir interés visual es justo en lo tocante a la observación apuntada al resto de los moradores y sus relaciones con el afuera en las relaciones de cotidianidad sin su presencia. Aun así, la contemplación sobre la intimidad propia resulta realmente poco usual y en cierto modo puede decirse que equivale a la mirada narcisista si se piensa la casa como extensión personal, lo cual históricamente no es inexacto en los orígenes de la función del hogar desde la Antigüedad clásica, en la que se establecía una identificación de patronazgo y dominio sobre los bienes y esclavos ahí contenidos (Echeverría, 1999).

Puede por tanto pensarse la mirada sobre la casa propia como una forma de control, sin ser irreductible, porque la actividad también deriva en algún grado impreciso de fruición. Ello puede apreciarse claramente en Ramón, el hermético voyeur de la mencionada comedia Kika. Se trata de un personaje definitivamente psicologizado, como suelen ser los del director manchego, cuya escoptofilia se explica con un trauma acarreado desde la infancia -el intempestivo y violento suicidio de su madre tras una relación tormentosa con su esposo, el padrastro de Ramón, un bohemio escritor estadounidense llamado Nicholas Pierce (Peter Coyote)-. Tras su muerte, el joven conoce y entabla una relación con la lenguaraz Kika (Verónica Forqué), una esteticista algo mayor que él, con dificultades de relación por su carácter reservado y obsesionado con la madre. Su trauma, relacionado con la visión de su agonía, lo lleva a desarrollar una escoptofilia manifiesta en su actividad visual profesional de fotógrafo que lleva hasta la intimidad que filma con Kika. Gómez Gómez señala al respecto que esa voracidad del personaje es comparable con la hipervisualización de la televisión, medio que ocupa un lugar central en la película desde una ironía crítica especialmente incisiva, como exceso que cae en el esperpento (2010, p. 14). Aun así, la escoptofilia de Ramón no se basta con esos consentidos momentos, porque alquila un piso de los tantos bloques de edificios en Madrid que da directo al suyo, ya que le produce placer mirarla a hurtadillas. Más porque Claude funciona como una evocación del enigmático visitante de Teorema (1968) de Pier Paolo Pasolini, como una presencia seductora que trastoca la normalidad doméstica. Y los estragos que deja tras de sí lo acercan -como es posible apreciar en algún ocasional close up- a un siniestro ángel exterminador que en su caso conduce al desalojo de los personajes asentados en una cómoda posición social. adelante, al verse Ramón obligado a dar cuenta de su conducta a la policía, comenta, no sin embarazo, que le gustaba mirar a su chica mientras se encontraba sola.

Sí bien resulta una narración mucho menos psicologizada y más compleja de las relaciones humanas, es la primera de las historias del director Ventura Pons en su película Animals ferits (2006), titulada 1: Allegro Assai. Silvio. Claudia. Marcia. Como se anuncia desde entonces, este primer segmento de unos 20 minutos cuenta la historia de un triángulo, donde el protagonista, Silvio Lisboa (José Coronado) se encuentra clandestinamente en el cuarto 6711 del Hotel Princesa Sofía con su amante Claudia 
Riera (Aitana Sánchez Gijón). La insistencia en que las citas sean siempre en esa misma habitación responde a una necesidad morbosa de Silvio porque justo desde ese emplazamiento observa la terraza de su burguesa morada desde donde puede mirar a su esposa Marcia (Cecilia Rossetto). En otras palabras, ese lugar le permite a Silvio atisbar, vigilar y controlar durante su ausencia el que al final de cuentas no deja de ser su territorio y sus posesiones: no en vano la película propone un parangón de los personajes con los animales -en concreto, heridos (para Pons) y tristes (para Jordi Puntí, el autor de la novela de donde procede la adaptación)-. Desde el emplazamiento que Silvio ha descubierto, la vigilancia y el control se ejercen fundamentalmente a través del sentido visual, el mismo que le permite obtener simultánea gratificación placentera, lo que comparte con el protagonista de Almodóvar.

Como Silvio, Ramón también se las agencia para una visión panorámica, pero no alquila la habitación de un hotel sino un apartamento desde cuya ventana instala un trípode que, al apuntar a la alcoba de la pareja, filma las 24 horas del día sin que ella se dé cuenta y sin que él esté necesariamente presente. Esa es la principal diferencia en la actividad voyeur de ambos personajes de Pons y Almodóvar: en el caso de Silvio está ligada sobre todo al instinto de macho cazador y territorial, en tanto que en Ramón es más patológica, vinculada con un trauma infantil claramente edípico. En su caso, la imagen captada tiene algunas diferencias con la de Silvio, por el instrumento con que capta a su presa: una cámara fotográfica -lo que conduce a un dominio de la imagen, de su acercamiento, repetición-, mientras que el protagonista del filme de Pons utiliza prismáticos o binoculares. Y además la de Ramón es una toma a nivel, no en angulación desde una ventana más alta y, por lo que se logra ver, desde el plano subjetivo del empresario que no accede al interior -limitado, claro- de la vivienda, solo a un fragmento, el terrado.

De hecho, precisamente es una de esas filmaciones la que le permite a Ramón percatarse del momento en que su propio hogar ha sido invadido por un individuo que en esos momentos viola a Kika y avisar a la policía, de labor incompetente. Ellos son quienes filtran las imágenes que se emiten en Lo peor del día, un programa sensacionalista de televisión creado y conducido por la excéntrica periodista Andrea Caracortada (Victoria Abril) y antigua novia de Ramón. Sátira de los espectáculos de telerrealidad -de aquellos que empezaban a pulular justamente a inicios de la década de los 90-, Lo peor del día se basa en la exposición espectacular de las intimidades de anónimos y se construye como una caricatura de la humillación televisiva en un filme que tiene una estructura paródica melodramática y continuada, en virtud del seguimiento a sus involucrados en posteriores transmisiones. Este fenómeno ha de entenderse como parte de las tendencias de exposición de la intimidad que proliferan de otras formas que entonces ni siquiera existían -como internet, los teléfonos móviles y las redes sociales-. Pero es que aparte de evidenciar una invasión de la antigua privacidad el fenómeno no deja de ser novedoso (Sibilia, 2013, p. 92).

Ciertamente Kika comparte con Animals ferits la visualización de la propia intimidad que, en el caso de Almodóvar, se propone como una violación por partida doble: sexualmente por un desconocido y, otra más sutil, visualmente por su propio compañero. Siendo un personaje desenfadado y de mente abierta, Kika se siente más afectada por lo que resulta una traición de Ramón. En ambos filmes los protagonistas (masculinos) funcionan como auténticos voyeurs, movidos por una necesidad ciertamente animal o pulsión irracional que los jalona a observar el espacio íntimo, acompañados de facilidades técnicas de artefactos específicos para contemplar una privacidad. Pero en estos dos casos, la particularidad de Silvio y de Ramón reside en que esa privacidad no es ajena sino propia, y los dos necesitan posicionarse desde cierta distancia, como si estuvieran haciendo las veces de un extraño, es decir, como si quien mirara no fueran ellos sino otros.

En el filme de Pons, la razón que explica el malestar de Claudia viene por el desencadenante del término de la relación movido por esa curiosidad visual de Silvio. Pero Claudia lo hace distinto: logra franquear el hermético acceso impuesto por su amante a su recelosa intimidad (a quien le reprocha que a pesar de llevar juntos un año no suela hablar sobre su vida) y penetrar físicamente al territorio de su amante. En el relato de Puntí, este se encuentra ubicado en Pedralbes, un barrio conocido por 
pertenecer a una de las zonas de mayor poder adquisitivo en Barcelona. Así que, bajo el pretexto de un reportaje, Claudia logra acceder al otro espacio privado de Silvio que conoce -el laboral bien frecuentado y nunca mejor dicho modelado por ella a raíz del contrato que le permitió conocerlo-. En la domesticidad tiene acceso a una franja más personal. Podría decirse que la suya es una forma de ingreso más inteligente y estudiado: una desconocida como ella pasa a adquirir un estatus de invitada prominente.

Pero el reportaje no se publicará -al final de cuentas no respondía más que a un interés personal, un pretexto caprichoso de hembra curiosa-. Y no se hará porque en realidad no es más que la estratagema de Claudia para husmear el auténtico territorio de su amante por todos los rincones hasta el tálamo en su sentido griego -el thalamós, el aposento más recóndito y más íntimo donde se guardan los tesoros personales más allá del lecho conyugal "que incluía unos bienes domésticos muy singulares y altamente definitorios de lo que es la raíz del hogar" (Echeverría, 1999, p. 29)-. El thalamós incluye, por supuesto, la cama king size que desenmascara a esta actualización del protagonista que le había confesado a Claudia que él y su esposa dormían en habitaciones separadas. Entre esos bienes, el principal, por supuesto, es la cama que da cuenta de la más profunda intimidad a la vez que desenmascara a esta actualización defraudada del don Juan (que le había mentido a su amante con que él y su esposa dormían en cuartos separados) al que no en vano el narrador llama "casanova grotesco".

No siempre se mantuvo en la historia este concepto de resguardo de los efectos personales. En la sociedad medieval, este concepto del dormitorio tenía un sentido más público que todavía no había evolucionado a otros usos menos privados, como sostiene Norbert Elías, donde el dormitorio se ha convertido en un ámbito más privado e íntimo de la vida humana:

Al igual que la mayor parte de las funciones corporales, también el "dormir" es algo que se ha ido relegando cada vez más, a la trastienda del trato social... En la sociedad medieval esta función todavía no se había privatizado tanto, ni se había excluido de la vida social... Era muy frecuente que muchas personas pasaran la noche en la misma habitación; en la clase alta lo hacía el señor con sus criados y la señora con su doncella o doncellas; en las otras clases solían dormir en la misma habitación hombre y mujeres juntos y hasta también los huéspedes que allí pernoctaran. (1989, p. 203)

Pero en el siglo XVIII la casa había ido dejando de ser un lugar de trabajo y se había ido haciendo más pequeña y menos pública, convirtiéndose en una protección contra los intrusos (Rybczynski, 2009, p. 85). Así se produce la división espacial de los aposentos, en el que el dormitorio fue reservándose a espacios interiores y privados. Precisamente ese recinto que ha perdido la connotación grupal y se ha interiorizado como personal, como thalamós, propicia el hecho de que Marcia le participe a alguien que acaba de conocer un comentario más apropiado para una amiga o una confidente próxima (Figura 4). Es una observación en torno a la calidad sexual de su esposo partiendo de la ponderación del tamaño del lecho nupcial -que hereda de la Edad Media su función social de ostentación (Elías, 1989, p. 203)-: "Con Silvio todo es king size... ¿ te puedo tutear?". Lejos de ser abrupto, el cambio de tema por la pregunta de la forma de referencia, esa forma verbal que denota cercanía de tratamiento, inmediatamente seguido de la confidencia íntima, está favorecido sin duda por el marco del thalamós.

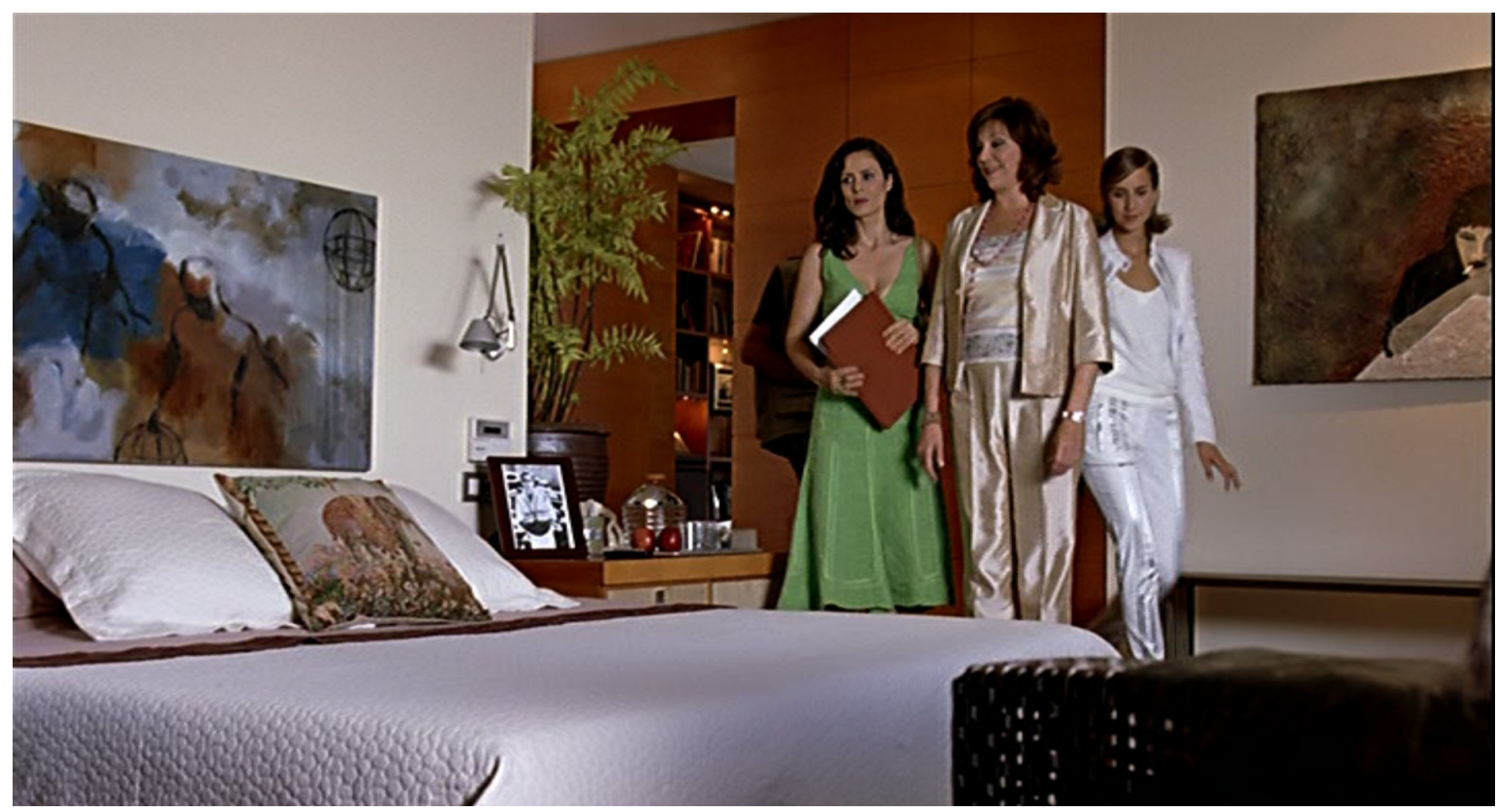


Entonces, desde conductas igualmente animales -husmear el territorio ajeno-, la relación, que tenía más de animal que de otra cosa, queda herida de muerte. La especie humana, de nuevo, se revela bastante más compleja.

\section{Final}

Podría antojarse incurrir en el apriorismo de que el interior de las casas no consiste más que en un cascarón que alberga objetos y moradores, pero estas representaciones fílmicas dan cuenta de detalles que intervienen y que pasan no solo por la comodidad y el gusto, sino por quien las habita, de la complejidad de su psique. No solo, pues, la casa da cuenta de lo que hay sino también de su ausencia, de la falta de su morador. A todo ello, aquí se ha partido de una variable adicional que funciona como eje articulador: la visión del personaje tanto sobre su propia casa como sobre la casa del otro, casi siempre del vecino. En el conjunto de filmes estudiados básicamente se mantiene un hecho básico común: que el sujeto en cuestión no se siente cómodo en su realidad doméstica y para ello necesita imponer un distanciamiento que le permita huir de su entorno, no necesariamente porque lo perciba agobiante ni tampoco por aburrimiento, sino por la fruición en el acto de mirar. Aun en el personaje de Leonardo, que más bien no quiere una ventana enfrente de la suya -porque constituye su negativo, la fuente en que se resiste a mirarse-, no puede evitar fisgonear al vecino que en el fondo menosprecia.

El personaje de Ozon, Claude García, es el caso ejemplar de quien parece que fue de niño abandonado por su madre y al verse destinado a cuidar a su padre inválido en una existencia rutinaria logra encontrar una salida a través de la observación y narración de lo que en última instancia constituye su falta. Lo hace en un escrito continuo, complementado con su imaginación y la guía pertinaz de su profesor Germaine. Desea obsesivamente ser parte de esa familia, aunque no termina de estar claro si en el lugar edípico del padre o en el del hijo. En ambos espacios se siente, eso sí, más cómodo que en el suyo propio. Como Jeff de Hitchcock, Claude también recurre a la visión de la casa ajena para evadir una realidad que perciben como monótona y aburrida. Pero mientras Jeff está en su piso pertrechado con equipo que permite ampliar la visión, Claude logra entrar y moverse por la casa como si fuera suya.

En el caso en cambio de quien, como Silvio de Pons o Ramón de Kika, ejercen esa visión no sobre la casa del vecino sino sobre la suya propia, es decir, en su necesaria ausencia, hay un placer de tipo más mórbido, relacionado con el espacio donde tiene lugar su desempeño sexual. En estos dos filmes de Pons y Almodóvar, el placer pasa por la mediación de la ventana y el vacío en relación con lo contemplado, lo que supone una nueva vuelta a la película de Hitchcock que Jeff sufre en carne propia. Ese vacío y esa caída supone un peligro ${ }^{5}$ y no es casual que ponga a ambos personajes en situaciones límite, como muestra la reacción de las parejas respectivas-Claudia y Kikaque no soportan la distancia de la visión interpuesta y encuentran en la revelación el detonante de la separación. La visión tiene que ver, en definitiva, con el emplazamiento y la casa desde donde el hombre ejerce el poder -ligado a una función animal, atávica: la visión- y termina tambaleándose.

\section{Fichas técnicas} con la imagen imposible de la rueda del coche de carreras directo a la visión del fotógrafo y como también inauguraba uno de sus films anteriores, Vértigo (1954), con un protagonista colgando del alero de una ventana, lo que condensaba la trama y cifraba su trauma.

\section{La ventana indiscreta (Rear Window,1954)}

Director: Alfred Hitchcock

Reparto: James Stewart (L. B. Jefferies), Grace Kelly (Lisa), Thelma Ritter (Stella), Raymond Burr (Lars Thorwald), Wendell Corey (Tom Doyle)

Productora: Paramount Pictures

Argumento: En un edificio de apartamentos de Greenwich Village el fotógrafo L. B. Jefferies se encuentra convaleciente de un accidente que lo ata a una silla de ruedas por su pierna escayolada. Recibe las visitas de su novia Lisa y de su masajista Stella. 
Se dedica a mirar por la ventana a sus vecinos hasta que cree que uno de ellos, Lars Thorwald, ha asesinado a su esposa, aunque no tiene evidencias.

Kika (1993)

Director: Pedro Almodóvar

Reparto: Verónica Forqué (Kika), Peter Coyote (Nicholas), Victoria Abril (Andrea Caracortada), Rossy de Palma (Juana), Anabel Alonso (Amparo), Bibiana Fernández (Susana), Àlex Casanovas (Ramón), Jesús Bonilla (policía), Karra Elejalde (policía)

Productora: El Deseo / Ciby 2000

Argumento: Kika, una maquilladora optimista y vital, vive con Ramón, un fotógrafo muy introvertido y obsesionado por la muerte de su madre que revive su trauma con el regreso de su padrastro, el escritor estadounidense Nicholas Pierce. La ex novia de Ramón, Andrea Caracortada, que tiene un show televisivo, reaparece en su vida cuando proyecta en su programa la violación de Kika por el hermano de su asistenta Juana (Rossy de Palma).

Animales heridos (Animals ferits, 2006)

Director: Ventura Pons

Reparto: José Coronado (Silvio Lisboa), Aitana Sánchez- Gijón (Claudia), Cecilia Rossetto (Marcia), Marc Cartes (Daniel), Cristina Plazas (Irina), Patricia Arredondo (Mariela), Gerardo Zamora (Jorge Washington),

Productora: Els Films de la Rambla

Argumento: En tono de tragicomedia, se narran tres historias dramáticas cuyos personajes se entrecruzan: Silvio Lisboa, un empresario de éxito que engaña a su esposa Marcia con la interiorista Claudia en el hotel Reina Sofía; la recepcionista de ese hotel que en unas vacaciones en Cadaqués engaña a su esposo y la asistenta suramericana de los Lisboa que aprovecha un fin de semana de ausencia de sus patrones para verse con su novio Jorge Washington quien más bien se ve atraído por las mujeres de Barcelona.

En la casa (Dans la maison, 2012)

Director: François Ozon

Reparto: Fabrice Luchini (Germain), Ernst Umhauer (Claude), Kristin Scott Thomas (Jeanne), Emmanuelle Seigner (Esther), Denis Menochet (Rapha Artole padre), Bastien Ughetto (Rapha Artole hijo)

Productora: Mandarin Production

Argumento: Un profesor frustrado de literatura francesa, Germain, encuentra en su curso de instituto a un estudiante (Claude) que sobresale del grupo por sus tareas interesantes. Son redacciones sobre vivencias donde narra secuencialmente su vivencia con uno de sus compañeros, Rapha Artole, en su casa con sus padres, Esther y Rapha padre. Poco a poco Claude se va involucrando y Germain se introduce personalmente a través de las tareas de su estudiante.

El hombre de al lado (2009)

Directores: Mariano Cohn y Gastón Duprat

Reparto: Rafael Spregelburd (Leonardo), Daniel Aráoz (Víctor), Eugenia Alonso (Ana)

Productora: Aleph Media

Argumento: Se trata de un conflicto entre vecinos a partir de una pared que divide las viviendas: Leonardo, un prestigioso diseñador y profesor universitario que vive en la famosa casa Curutchet, la única diseñada por Le Corbusier en América, y su vecino Víctor, un tipo de maneras rústicas, vendedor de coches usados e intimidante. La molestia se genera cuando este abre un boquete porque quiere más iluminación en su vivienda y evidencia su presencia en la vida de Leonardo. 


\section{Referencias Bibliográficas}

Almodóvar, P (Director). (1993). Kika. Madrid: El deseo.

Ariès, P. \& Duby, G. (2001). Historia de la vida privada. 5. De la Primera Guerra Mundial hasta nuestros días. Madrid: Taurus.

Bordwell, D., Staiger, J. \& Thompson, K. (1997). El cine clásico de Hollywood. Estilo cinematográfico y modo de producción hasta 1960. Barcelona: Paidós.

Centro de cultura contemporánea de Barcelona (CCCB). (2016). $1000 \mathrm{~m}^{2}$ de deseo. Arquitectura y sexualidad. Barcelona: Centro de Cultura Contemporánea de Barcelona y Gabinete de prensa y comunicación de la Diputación de Barcelona.

Cohn, M. \& Duprat, G (Directores) (2009). El hombre de al lado. Argentina: Aleph Media.

Echeverría, J. (1999). Cosmopolitas domésticos. Barcelona: Anagrama.

Elías, N. (1989). El proceso de la civilización. Investigaciones sociogenéticas y psicogenéticas. México: Fondo de Cultura Económica.

Gómez Gómez, A. (2010). "Andrea Caracortada y el modelo de televisión en Pedro Almodóvar", Actas - II Congreso Internacional Latina de Comunicación Social, Universidad La Laguna.

González Requena, J. (1989). "Viendo mirar. Mirada y punto de vista en el cine de Hitchcock", documento mimeografiado.

Hitchcock (Director), A. (1954). Rear Window. Estados Unidos: Paramount.

Marías, J. (1989). Todas las almas. epubLibre. Edición de Kindle.

Métraux, G. (1999). "Ancient Housing: Oikos and Domus in Greece and Rome", Journal of the Society of Architectural Historians, 58(3), 392-405.

Mitchell, W. J. T. (1996). What Do Pictures Really Want?, 77, 71-82.

Mouguillansky, M. (2014). Metáforas de la desigualdad social. Una lectura de El hombre de al lado, A contracorriente, 11(2), 145-165.

Mulvey, L. (1988). Placer visual y cine narrativo. Valencia: Fundación Instituto Shakespeare.

Navarro de Zuvillaga, J. (2000). Mirando a través. La perspectiva en las artes. Barcelona: Ediciones del Serbal.

Ozon, F (Director). (2012). Dans la maison. Francia: Mandarin Cinéma / Mars Films / France 2 Cinéma / Foz / Canal + / Ciné + / France Telévisions / Cofimage 23 / Palatine Étoile.

Pacteau, F. (1994). The Symptom of Beauty. Cambridge - Massachusetts: Harvard University Press.

Pons, V (Director). (2006). Animals ferits. Barcelona: Els Films de la Rambla.

Puntí, J. (2004). Animales tristes. Barcelona: Salamandra.

Rybczynski, W. (2009). La casa. Historia de una idea. Donostia: Nerea.

Sanabria, C. (2012). Contemplación de lo íntimo. Madrid: Biblioteca Nueva.

Sibilia, P. (2013). La intimidad como espectáculo. México: Fondo de Cultura Económica.

Vélez de Guevara, L. (2011). El diablo cojuelo. Madrid: Cátedra.

Woolrich, C. (1973). La ventana indiscreta y otras narraciones. Barcelona: Acervo.

Žižek, S. (comp.) (1994). Todo lo que usted siempre quiso saber sobre Lacan y nunca se atrevió a preguntarle a Hitchcock. Argentina: Manantial. 